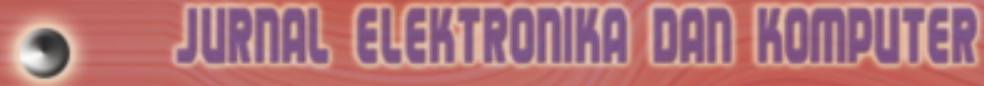

Analisis Pemakaian Sensor Loadcell Dalam Perhitungan Berat Benda Padat dan Cair Agus Wibowo Agus Wibowo

Rancang Bangun Sistem Keamanan Sepeda Motor Menggunakan Rfid dan Personal Identification Number (Pin) Berbasis Mikrokontroler Atmega16

Galang Yudha Murih Raharja, Padjar Setyobudi

Sistem Pencegah Kebakaran Pada Perkebunan Jambu Biji Menggunakan Sensor Suhu Lm35 dan Sms Gateway Berbasis Arduino Uno Kelik Bayu Susatyo

Jurnal ELKOM diterbitkan oleh Sekolah Tinggi Elektronika dan Komputer (STEKOM). Jurnal ELKOM sebagai sarana komunikasi dan penyebarluasan hasil penelitian, pemikiran serta pengabdian pada masyarakat

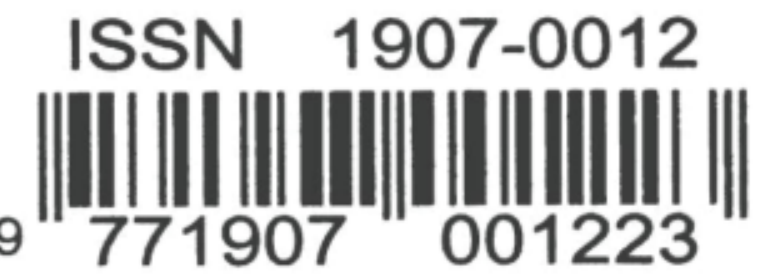

STEKOM

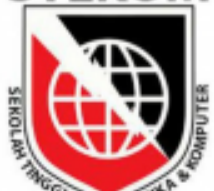
Sekolah Tinggi Elektronika dan Komputer SEMARANG 


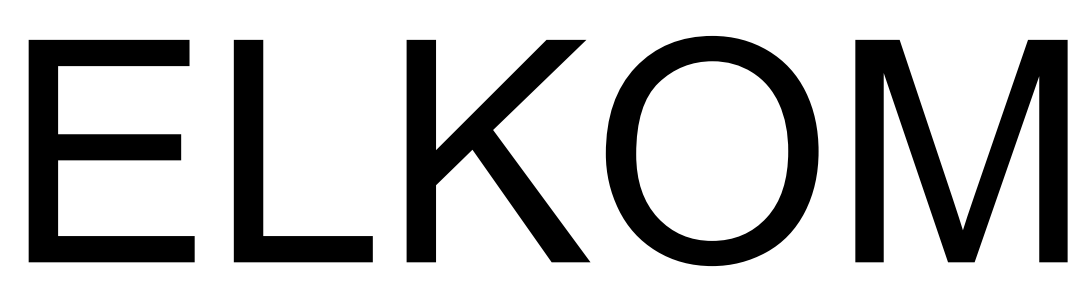

JURNAL ELEKTRONIKA DAN KOMPUTER

Penanggung Jawab :

Ketua Sekolah Tinggi Elektronika \& Komputer

Pemimpin Redaksi :

Sulartopo, S.Pd, M.Kom

Penyunting Pelaksana:

Dr. Ir. Drs. R. Hadi Prayitno, S.E, M.Pd

Dr. Ir. Agus Wibowo, M.Kom, M.Si, M.M

Sarwo Nugroho, S.Kom, M.Kom

Sekretaris Penyunting:

Ir. Paulus Hartanto, M.Kom

Mars Caroline Wibowo, S.T, MT. Tech

Sekretariat :

Dr. Unang Achlison, S.T, M.Kom

Djoko Soerjanto, S.E, M.Kom

Muhammad Sidik, S.Kom, M.Kom

Desain Grafis :

Setiyo Adi Nugroho,S.E, S.Kom

\section{Alamat Redaksi : \\ Pusat Penelitian - Sekolah Tinggi Elektronika \& Komputer (STEKOM) Jl. Majapahit No. 605 Semarang Telp. 024-6710144 E-Mail : \\ elkom@stekom.ac.id}




\section{KATA PENGANTAR}

Puji syukur ke hadirat Tuhan Yang Maha Esa dengan terbitnya Jurnal elektronika dan computer (ELKOM) Edisi Maret 2019, Volume 12 Nomor 1 Tahun 2019 dengan artikel-artikel yang selalu mengikuti perkembangan IImu Pengetahuan dan Teknologi dalam bidang elektronika dan computer. Semua artikel yang dimuat pada Jurnal elektronika dan komputer (ELKOM) ini telah ditelaah oleh Dewan Redaksi yang mempunyai kompetensi di bidang elektronika dan komputer. Pada edisi ini kami menyajikan beberapa topik menarik tentang penerapan elektronika dan komputer yaitu: "Analisis Pemakaian Sensor Loadcell Dalam Perhitungan Berat Benda Padat dan Cair Berbasis Microcontroller", serta "Rancang Bangun Sistem Keamanan Sepeda Motor Menggunakan RFID dan Personal Identification Number (Pin) Berbasis Mikrokontroler Atmega16", selanjutnya "Sistem Pencegah Kebakaran Pada Perkebunan Jambu Biji Menggunakan Sensor Suhu LM35 dan SMS Gateway Berbasis Arduino Uno ", dan "Sistem Pengendalian Suhu Air Nutrisi Hidroponik Nft (Nutrient Film Tehnique) Menggunakan Sensor Suhu Dan Sms Gateway Berbasis Arduino (Studi Kasus Di Siliwangi Indah Hidroponik)". Terima kasih yang mendalam disampaikan kepada penulis makalah yang telah berkontribusi pada penerbitan Jurnal ELKOM edisi kali ini. Dengan rendah hati dan segala hormat, mengundang Dosen dan rekan sejawat peneliti dalam bidang elektronika dan komputer untuk mengirimkan naskah, review, gagasan dan opini untuk disajikan pada Jurnal elektronika dan komputer (ELKOM) ini. Sebagai akhir kata, saran dan kritik terhadap Jurnal elektronika dan komputer

(ELKOM) yang membangun sangat diharapkan. Selamat membaca.

Semarang, Maret 2019 


\section{DAFTAR ISI}

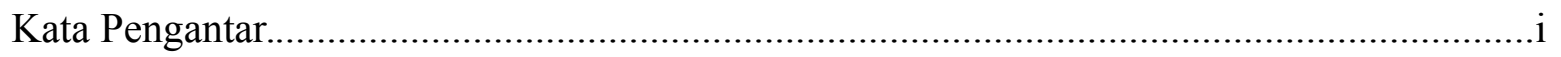

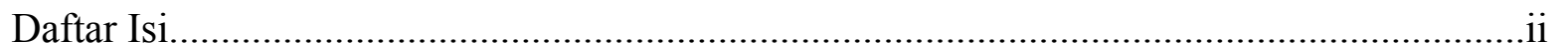

1 Analisis Pemakaian Sensor Loadcell Dalam Perhitungan Berat Benda Padat dan Cair Berbasis Microcontroller, Agus Wibowo...................................... $1-5$

2 Rancang Bangun Sistem Keamanan Sepeda Motor Menggunakan RFID dan Personal Identification Number (Pin) Berbasis Mikrokontroler Atmega16, Galang Yudha Murih Raharja ,Padjar Setyobudi

3 Sistem Pencegah Kebakaran Pada Perkebunan Jambu Biji Menggunakan Sensor Suhu LM35 dan SMS Gateway Berbasis Arduino Uno, Kelik Bayu Susatyo

4 Sistem Pengendalian Suhu Air Nutrisi Hidroponik Nft (Nutrient Film Tehnique) Menggunakan Sensor Suhu Dan Sms Gateway Berbasis Arduino (Studi Kasus Di Siliwangi Indah Hidroponik), Nurul Khabib Allin 


\title{
Sistem Pengendalian Suhu Air Nutrisi Hidroponik Nft (Nutrient Film Tehnique) Menggunakan Sensor Suhu Dan Sms Gateway Berbasis Arduino (Studi Kasus Di Siliwangi Indah Hidroponik)
}

\author{
Nurul Khabib Allin \\ Program Studi S1 Sistem Komputer \\ Sekolah Tinggi Elektronika dan Komputer \\ Email : habiballin@gmail.com
}

\begin{abstract}
ABSTRAK
Hidroponik saat ini semakin diminati, harus dilakukan pengecekan secara rutin agar tanaman hidroponiknya tumbuh subur. Begitu juga di Siliwangi Indah Hidroponik Semarang yang masih menggunakan metode manual, yaitu tidak adanya alat yang mendeteksi suhu air nutrisi dan $\mathrm{pH}$ secara otomatis dan tidak adanya alat yang bisa menormalkan nutrisi dengan otomatis.Arduino Uno R3 dapat digunakan untuk mendeteksi suhu secara otomatis dengan sensor suhu DS18B20, dan mendeteksi pH dengan sensor $\mathrm{pH}$. Kemudian hasil pembacaan sensor di kirim ke handphone petani denganSMS Gateway. Hasil pembacaan sensor itu juga digunakan untuk mengalihkan aliran nutrisi dari tandon cadangan, sehingga nutrisi tetap normal.Jadi alat ini bisamengukursuhu air nutrisi dan $\mathrm{pH}$ secara otomatis danmengganti nutrisi utama ke nutrisi cadangan. Serta penilaian yang didapat dari pakar terhadap alat ini mendapat nilai 3,6 dan dari ahli mendapat nilai 3,7. Nutrisi hidroponik pada penelitian ini tetap terjaga normal dan petani selalu mengetahui keadaan nutrisinya. Sehingga tanaman hidroponiknya tumbuh subur dan maksimal hasil panennya.
\end{abstract}

Kata kunci : Sensor Suhu DS18B20, Sensor Ph, SMS Gateway, Arduino Uno R3.

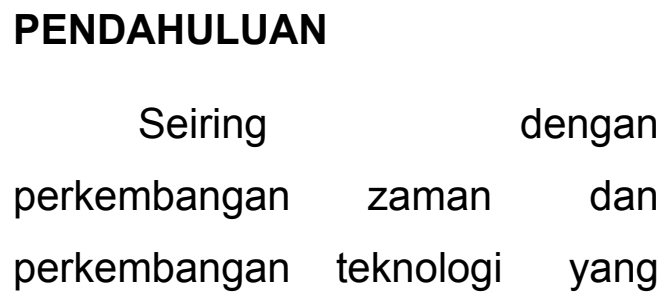

semakin maju, kebutuhan
masyarakat akan alat-alat
kebutuhan tertentu juga semakin
meningkat. Maka banyak alat


Sistem Pengendalian Suhu Air Nutrisi Hidroponik Nft (Nutrient Film Tehnique) Menggunakan Sensor Suhu Dan Sms Gateway Berbasis Arduino, , Vol 12, No.1, Maret 2019.

yang diciptakan dengan teknologi yang inovatif sebagai penunjang kebutuhan masyarakat.Baik digunakan untuk keperluan bisnis, instansi pemerintah, akademik dan masih banyak lagi.Banyak dari instansi-instansi perusahaan dan masyarakat yang semakin menggantungkan kebutuhan pada teknologi untuk mempermudah pekerjaan dan bisa juga sebagai alat keamanan untuk perusahaan dan masyarakat.Hal ini membuat manusia berlomba-lomba untuk menciptakan alat-alat dengan teknologi terbaru.Termasuk teknologi yang di aplikasikan dalam bertanam hidroponik. Pada tempat penelitian di

Siliwangi Indah Hidroponik yang beralamat di Jln. Siliwangi 379 Perum PLN No. 15 RT.01 RW.01 Purwoyoso Ngaliyan Semarang yang sudah lama menggeluti bisnis sayuran hidroponik. Siliwangi indah hidroponik pada awalnya adalah dari hobi.Di siliwangi indah hidroponik menanam berbagai sayuran yang umumnya dibutuhkan oleh masyarakat Semarang, salah satunya sayuran sledri.Sayuran sledri di siliwangi indah hidroponik ditanam semenjak dari pembibitan sampai sayuran tersebut siap di pasarkan.Sistem hidroponik yang dipakai adalah sistem NFT (Nutrient Film

Tehnique). Faktor yang diperhatikan pada sistem tersebut adalah dalam pengaturan $\mathrm{PH}$, nutrisi yang dibutuhkan, suhu, kadar sinar matahari dan yang lainnya. Di siliwangi indah hidroponik terdapat 3 pengelola atau petani yang sudah ahli dibidang pertanian hidroponik.

Permasalahan yang terjadi pada siliwangi indah hidroponik adalah pengecekan $\mathrm{pH}$ dan suhu nutrisinya masih dengan metode manual.Pengelola menggunakan alat portable untuk mengeceknya, sehingga mudah terjadi kelalaian dari pengelolanya. Karena setiap pagi, siang dan sore harus melakukan 
Sistem Pengendalian Suhu Air Nutrisi Hidroponik Nft (Nutrient Film Tehnique) Menggunakan Sensor Suhu Dan Sms Gateway Berbasis Arduino, , Vol 12, No.1, Maret 2019.

$$
\begin{aligned}
& \text { pengecekanrutin. Juga } \\
& \text { terjadi permasalahan } \\
& \text { peningkatan suhu nutrisi } \\
& \text { diujung pipa PVC > } 35^{\circ} \\
& \text { celcius yang disebabkan } \\
& \text { oleh sinar matahari yang } \\
& \text { berlebih pada siang hari. } \\
& \text { Hal itu akan menyebabkan } \\
& \text { air yang berada pada } \\
& \text { tandon juga menjadi panas } \\
& \text { dan menyebabkan }
\end{aligned}
$$$$
\text { tanaman menjadi kuning. }
$$$$
\text { Ditambah lagi belum }
$$$$
\text { adanya alat otomatis untuk }
$$$$
\text { mengetahui jika sewaktu- }
$$$$
\text { waktu nutrisi tidak }
$$$$
\text { mengalir yang disebabkan }
$$$$
\text { seperti matinya alat }
$$$$
\text { pemompa nutrisi. }
$$$$
\text { Maka dari itu }
$$

penulis memberikan solusi

yaitu dalam sistem

pengendalian suhu nutrisi

hidroponik NFT (Nutrient

Film Tehnique)

menggunakan sensor

suhu dan sms gateway

berbasis Arduino.Alat yang

mendukung dalam

penelitian ini yaitu Arduino

Uno R3, sensor suhu
DS18B20 (water proof), Pompa dan GSM shield. Prinsip kerja pada saat alat diaktifkan seketika itu juga akan bekerja, jika sensor suhu tersebut mendeteksi air nutrisi yang mengalir di ujung pipa PVC tersebut mencapai $>35^{\circ}$ celcius, maka Pompa akan mengalirkan air nutrisi yang suhunya masih normal. Sebuah pesan akan dikirim melalui sms gateway yang memberitahukan seluruh keadaan yang terjadi di tanaman hidroponiknya ke handphone pengelola. Pemberitahuan tersebut berisi keadaan $\mathrm{pH}$ dan suhu nutrisi hidroponiknya.Serta dibutuhkan alat yang otomatis menggantikan suplay listrik jika terjadi pemadaman listrik. Jadi kesimpulan dari keterangan diatas adalah alat tersebut akan menormalkan suhu yang 
Sistem Pengendalian Suhu Air Nutrisi Hidroponik Nft (Nutrient Film Tehnique) Menggunakan Sensor Suhu Dan Sms Gateway Berbasis Arduino, , Vol 12, No.1, Maret 2019.

mengalami peningkatan, otomatis memberitahukan semua keadaan yang terjadi di tanaman hidroponiknya seperti berapa kadar suhu air nutrisinya, pHnya, melalui GSM shield yang dikirimkan ke handphone pengelola dengan no yang sudah terdaftar.

\section{METODOLOGI PENELITIAN}

Model pengembangan yang digunakan adalah dengan metode pengembangan yang berdasarkan pertimbangan kecocokan dan sifat penelitian yang dilaksanakan, yaitu dengan metode Research and Development (R\&D), penelitian ini terdiri dari beberapa tahap, yaitu sebagai berikut :

a. Potensi dan masalah, penelitian berawal dari adanya potensi atau masalah.

Potensi adalah segala
sesuatu yang bila
didayagunakan akan memiliki
nilai tambah. Masalah juga
bisa dijadikan sebagai

potensi, apabila dapat

mendayagunakannya.

Masalah akan terjadi jika

terdapat penyimpangan antara yang diharapkan dengan yang terjadi. Masalah ini dapat diatasai melalui $R$ \& D dengan cara meneliti sehingga dapat ditemukan suatu model, pola atau system penanganan terpadu yang efektif yang dapat digunakan untuk mengatasi masalah tersebut.

b. Pengumpulan data, setelah potensi dan masalah selanjutnya dikumpulkan berbagai informasi dan studi literatur yang dapat digunakan sebagai bahan untuk perencanaan produk tertentu yang diharapkan dapat mengatasi masalah tersebut. Studi ini ditujukan untuk menemukan konsep-konsep atau landasan-landasan teoritis yang memperkuat suatu produk. Di sisi lain studi literatur akan dikaji ruang lingkup suatu produk, keluasan penggunaan, 
Sistem Pengendalian Suhu Air Nutrisi Hidroponik Nft (Nutrient Film Tehnique) Menggunakan Sensor Suhu Dan Sms Gateway Berbasis Arduino, , Vol 12, No.1, Maret 2019.

kondisi-kondisi optimal, serta keunggulan dan keterbatasannya. Studi literature juga diperlukan untuk mengetahui langkahlangkah yang paling tepat dalam pengembangan produk tersebut.

C. Desain produk, produk yang dihasilkan dari penelitian $\mathrm{R}$ \& D ada banyak macamnya. Untuk menghasilkan sistem kerja baru harus dibuat rancangan kerja baru berdasarkan penilaian terhadap sistem kerja lama, sehingga dapat ditemukan kelemahan-kelemahan terhadap sistem tersebut, disamping itu dilakukan penelitian terhadap unit lain yang dipandang sistem kerjanya bagus dan harus mengkaji referensi mutakhir yang terkait dengan sistem kerja yang modern serta indikator sistem kerja yang baik. Hasil akhir dari kegiatan ini berupa desain produk baru yang lengkap dengan spesifikasinya. Desain ini masih bersifat hipotetik karena efektivitasnya terbukti, dan akan dapat diketahui setelah melalui pengujianpengujian. Desain produk harus diwujudkan dengan gambar atau bagan, sehingga dapat digunakan sebagai pegangan untuk menilai dan membuatnya, serta akan memudahkan pihak lain untuk memahaminya.

d. Validasi desain, merupakan proses kegiatan untuk menilai apakah rancangan produk dalam hal ini sistem kerja baru secara rasional akan lebih efektif dari yang lama atau tidak. Dikatakan secara rasional, karena validasi disini masih bersifat penilaian berdasarkan pemikiran rasional, belum fakta lapangan.Validasi produk dapat dilakukan dengan cara menghadirkan beberapa pakar atau tenaga ahli yang sudah berpengalaman untuk menilai desain tersebut, sehingga selanjutnya dapat 
diketahui kelemahan dan kekuatannya.

e. Revisi desain, setelah desain produk divalidasi melalui diskusi dengan pakar dan para ahli lainnya. Maka akan dapat diketahui kelemahannya. Kelemahan tersebut selanjutnya dicoba untuk dikurangi dengan cara meperbaiki desain. Yang bertugas memperbaiki desain adalah peneliti yang telah menghasilkan produk tersebut.

f. Ujicoba produk, desain produk yang telah dibuat tidak bisa langsung diuji coba dahulu. Tetapi harus dibuat dahulu, menghasilkan produk dan produk tersenut yang diuji coba.Pengkajian dapat dilakukan dengan eksperimen yaitu membandingkan efektivitas dan efisiensi sistem kerja lama dengan yang baru.

g. Revisi produk, pengujian produk pada sampel yang terbatas tersebut menunjukkan bahwa kinerja sistem kerja baru ternyata yang lebih baik dari sistem lama. Perbedaan sangat signifikan, sehingga sistem kerja baru tersebut dapat diberlakukan.

h. Ujicoba pemakaian, setelah pengujian terhadap produk berhasil dan mungkin ada revisi yang tidak terlalu penting, maka selanjutnya produk yang berupa sistem kerja baru tersebut diterapkan dalam kondisi nyata untuk lingkup yang luas. Dalam operasinya sistem kerja baru tersebut tetap harus dinilai kekurangan atau hambatan yang muncul guna untuk perbaikan lebih lanjut.

i. Revisi produk, revisi ini didasarkan atas masukan dari uji coba pemakaian. Langkah ini akan semakin menyempurnakan produk yang sedang dikembangkan. Penyempurnaan produk akhir ini sudah didapatkan suatu produk yang tingkat efektivitasnya dapat dipertanggungjawabkan. 
Sistem Pengendalian Suhu Air Nutrisi Hidroponik Nft (Nutrient Film Tehnique) Menggunakan Sensor Suhu Dan Sms Gateway Berbasis Arduino, , Vol 12, No.1, Maret 2019.

j. Produksi masal, ini dilakukan apabila produk yang telah diuji coba dinyatakan efektif dan layak untuk diproduksi masal. Sebagai contoh pembuatan mesin untuk mengubah sampah menjadi bahan yang bermanfaat akan diproduksi masal apabila berdasarkan studi kelayakan baik dari aspek teknologi, ekonomi dan lingkungan memenuhi. Jadi untuk memproduksi peneliti dan pengusaha harus bekerja sama.

\section{HASIL DAN PEMBAHASAN}

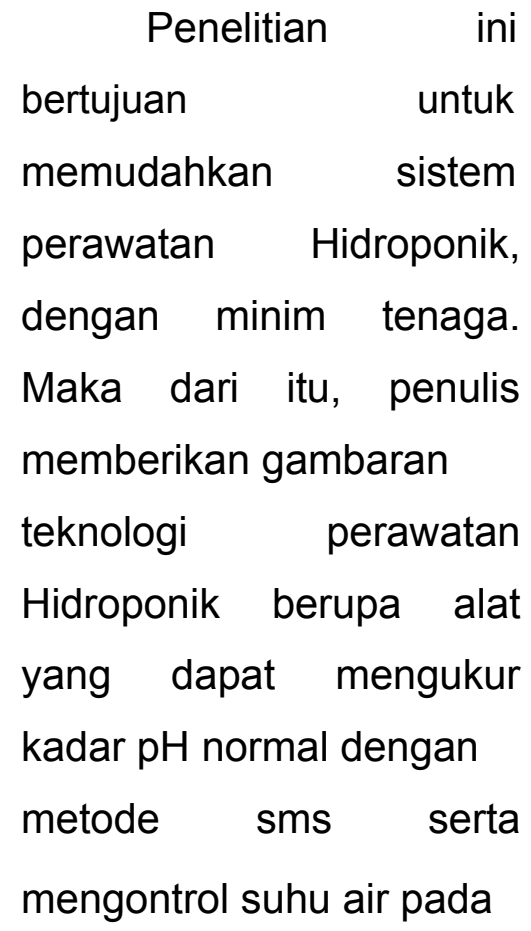

tandon agar tetap stabil

secara otomatis.

Prinsip kerja pada alat ini, pengguna hanya perlu mencolokkan ke stop kontak yang telah terintegrasi dengan sistem, setelah itu sistem akan langsung mengeksekusi proses perawatan Hidroponik yang telah terprogram. Saat listrik menyala, sensor suhu mendeteksi suhu air apakah suhu air tidak normal(>35derajat) maka led dan relay menyala kemudian akan mengirim sms kemudian air akan berganti secara otomatis agar suhu menjadi normal, sensor $\mathrm{pH}$ menyala medeteksi $\mathrm{pH}$ diatas 6 , led menyala dan mengirim sms .

Dari penjelasan di atas, perbedaan sistem lama dan baru terletak pada keterlibatan tenaga manusia. Sistem lama manusia sepenuhnya terlibat dalam proses perawatan Hidroponik, sedangkan pada sistem baru, kita akan merasa aman apabila hendak 
Sistem Pengendalian Suhu Air Nutrisi Hidroponik Nft (Nutrient Film Tehnique) Menggunakan Sensor Suhu Dan Sms Gateway Berbasis Arduino, , Vol 12, No.1, Maret 2019.

bepergian dalam jangka

waktu yang lama.

1.1 Skema Rancangan Yang Akan Dibangun

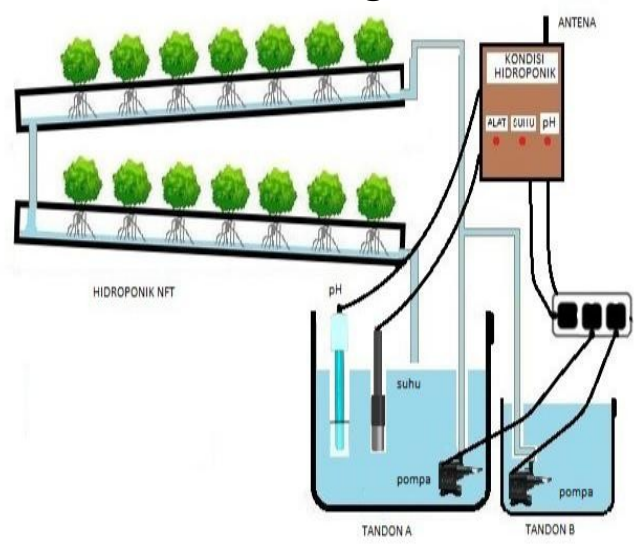

Gambar 1.Skema rancangan yang akan dibangun

Pada gambar 1.

menunjukkan rangkain alat dan hidroponik. Hidroponik dengan 2 nft, begitu juga tandon nutrisi juga 2, 2 pompa. Ketika suhu tidak normal maka pompa pertama akan mati dan pompa ke 2 hidup.

\subsection{Diagram Alur Kerja Alat}

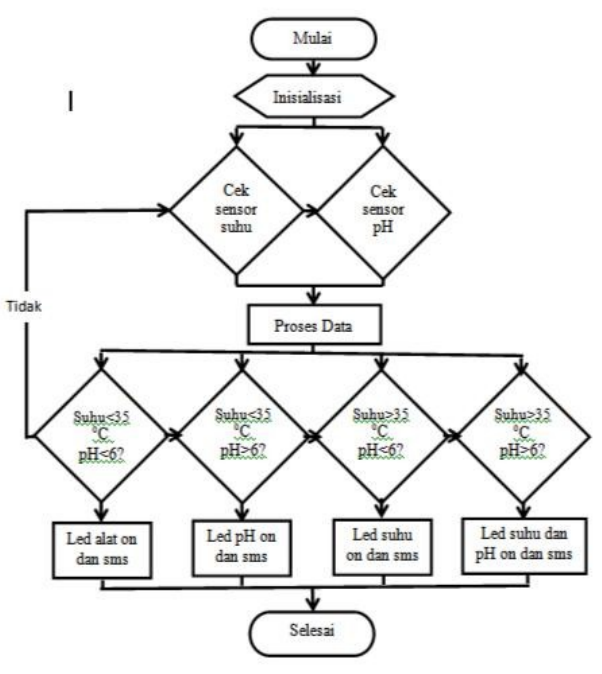

Gambar 2.Diagram alur kerja alat

Dari gambar 2. diatas, mulai dari inisialisasi GSM Shield kemudian cek sensor suhu, sensor $\mathrm{pH}$ pada sistem informasi Nutrisi Hidroponik apakah terjadi peningkatan suhu diatas normal, dan $\mathrm{pH}$ diluar normal? Jika "Ya" led on dan mengirim SMS secara otomatis dan kemudian akan mengganti pompa. Jika "Tidak" maka led off dan tidak mengirim SMS.

\subsection{Pengujian SensorSuhu}


Sistem Pengendalian Suhu Air Nutrisi Hidroponik Nft (Nutrient Film Tehnique) Menggunakan Sensor Suhu Dan Sms Gateway Berbasis Arduino, , Vol 12, No.1, Maret 2019.

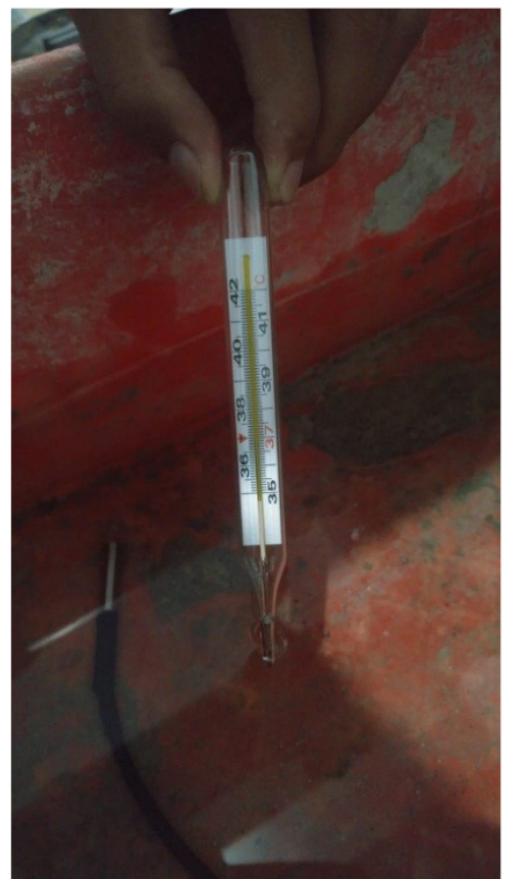

Gambar 3.Suhu nutrisi normal

Gambar 3.Menunjukkan sensor suhu berada didalam nutrisi. Nutrisi tersebut bersuhu normal yaitu $31^{\circ} \mathrm{C}$, jadi sensor suhu akan membaca keadaan suhu nutrisi dan selanjutnya data dari sensor dikirim ke arduino dan akan diproses oleh arduino.

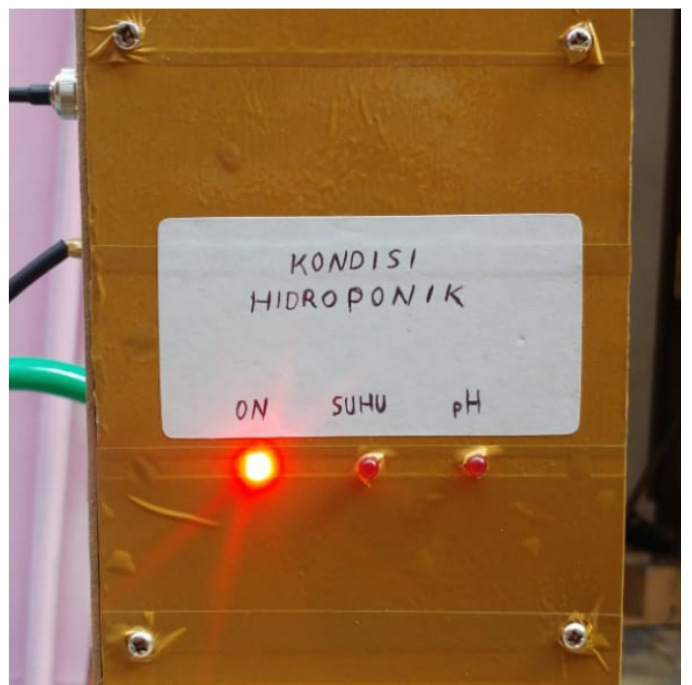

Gambar 4.Led suhu off

Gambar 4. Menunjukkan indikator alat yang menyala hanya led alat, yaitu hasil dari pemrosesan data oleh arduino.Sedangkan led suhu dan $\mathrm{pH}$ off, jadi itu menunjukkan suhu nutrisinya dalam keadaan normal.

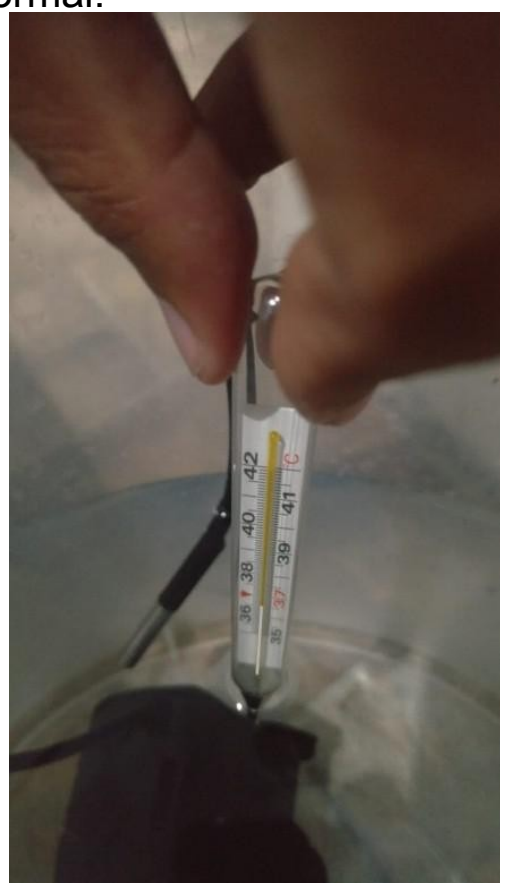


Sistem Pengendalian Suhu Air Nutrisi Hidroponik Nft (Nutrient Film Tehnique) Menggunakan Sensor Suhu Dan Sms Gateway Berbasis Arduino, , Vol 12, No.1, Maret 2019.

\section{Gambar 5. Suhu nutrisi tidak} normal

Gambar 5. Menunjukkan uji coba sensor suhu didalam nutrisi yang bersuhu tidak normal yaitu $36,5^{\circ} \mathrm{C}$, sehingga sensor menangkap data suhu dan diteruskan ke arduino untuk diproses.

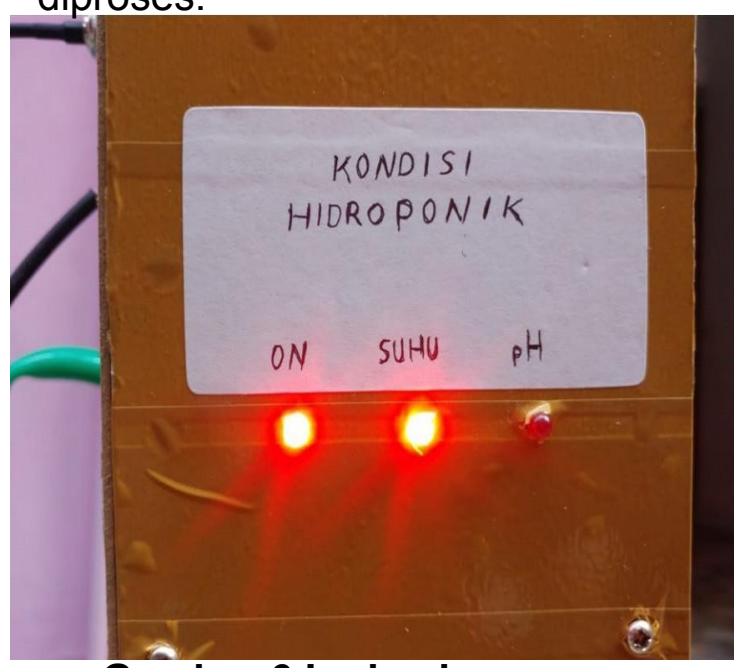

Gambar 6.Led suhu on

Gambar 4.5 menunjukkan setelah sensor suhu mendeteksi suhu tidak normal maka arduino memproses data dari sensornya dan menyalakan led suhu, yang berarti suhu air nutrisi tidak normal.

\subsection{Pengujian Sim900}

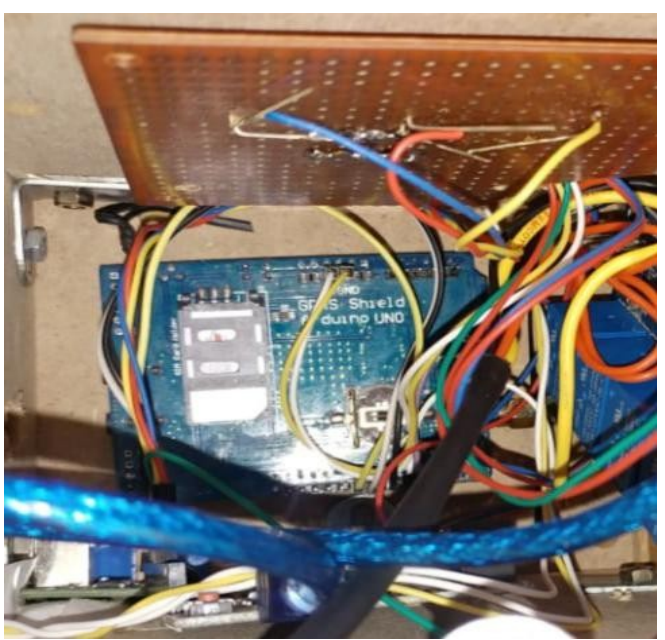

Gambar 11. sim900

Gambar 11. menunjukkan

modul sim900 didalam alat. Modul sim900 hanya akan mengirimkan sms jika arduino memerintahkan untuk mengirim sms. Sedangkan arduino memberikan perintah sms jika data yang diproses adalah data suhu dan atau $\mathrm{pH}$ yang tidak normal.

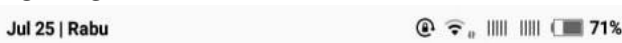

$(\oplus$

Hidroponik

081215518683 Indonesia

Alat Monitoring Hidroponik Siap

Digunakan.

Suhu Diatas 35 Derajat Celsius.

pH Diatas 6.

pH Diatas 6.

(1) type here...

\section{2}

Gambar 12.sms alat 
Sistem Pengendalian Suhu Air Nutrisi Hidroponik Nft (Nutrient Film Tehnique) Menggunakan Sensor Suhu Dan Sms Gateway Berbasis Arduino, , Vol 12, No.1, Maret 2019.

Gambar 12. menunjukkan sms dari alat ketika suhu dan $\mathrm{pH}$ tidak normal. Itu hasil dari perintah arduino kepada modul sim900 untuk mengirimkan sms, baik perintah sms suhu tidak normal dan atau $\mathrm{pH}$ tidak normal.

\subsection{Hasil Penelitian}

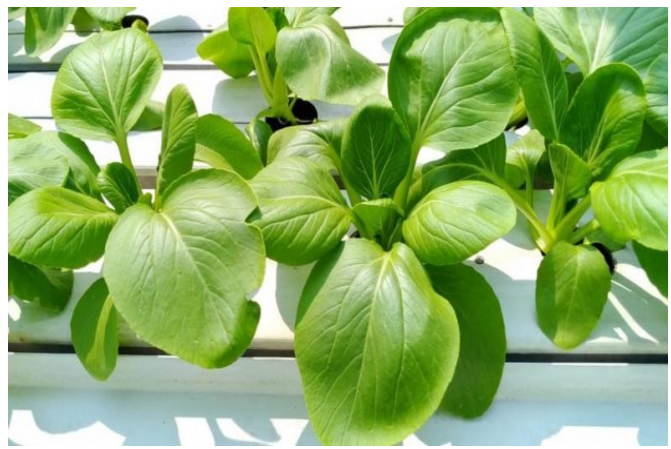

Gambar 16.sawi umur 3 minggu

Pada gambar 16 nampak tanaman sawi yang sudah siap dipanen. Daunnya sangat lebar dan banyak. Batangnya sangat besar. Akarnya juga sangat lebat.Dari hasil pengamatan langsung pada tanaman diatas semua tanaman terlihat subur dari semenjak pertama tanaman dipindah ke media tanam hidroponik sampai tanaman sudah berumur 3 minggu yang siap dipanen. Maka pengaruh alat yang penulis buat sangatlah membantu petani dalam merawat dan memantau tanaman hidroponiknya. Hasilnya tanaman lebih subur dan panen menjadi melimpah.

\section{KESIMPULAN}

Berdasarkan hasil pengujian yang dilakukan oleh pakar, produk ini mendapatkan nilai 3,6 yang tergolong sangat valid. Sedangkan pengujian oleh pemilik hidroponik mendapatkan nilai 3,7 yang juga tergolong sangat valid. Maka kesimpulan dari penelitian yang telah dilakukan adalah :

1. Rancangan yang dibuat oleh penulis dapat mengukursuhu air nutrisi dan $\mathrm{pH}$ secara otomatis, sehingga dapat memperkecil kemungkinan adanya bahaya nutrisi tidak normal.

2. Alat yang dibuat penulis dapatmengganti nutrisi ke nutrisi cadangan sehingga 
Sistem Pengendalian Suhu Air Nutrisi Hidroponik Nft (Nutrient Film Tehnique) Menggunakan Sensor Suhu Dan Sms Gateway Berbasis Arduino, , Vol 12, No.1, Maret 2019.

diharapkan dapat
meningkatkan tingkat
kesuburan tanaman.

3. Alat yang dibuat penulis dapat otomatis menyalakan suplay listrik cadangan sehingga alat akan tetap menyala walaupun terjadi pemadaman listrik utama.

4. Alat yang dibuat penulis dapat memberitahukan kepada petani secara otomatis.

\section{DAFTAR PUSTAKA}

Gerai Cerdas, 2014; “Digital

Temperature DS18B20

(Waterproof)",

Tangerang

:http://www.geraicerdas.co $\mathrm{m} /$ sensor/temperature/digit al-temperature-ds18b20waterproof-detail, diakses pada tanggal 21 Agustus 2016.

Hansen,, dan Mowen,, 2011;

"Akuntansi dan

Pengendalian Manajemen

Biaya”, Jakarta : Salemba Empat.
Jaya, Afrizal Eka, 2015;

“Joystick Wireles PS2

sebagaiPengontrol

Pemotong Rumputdengan

Driver Relay Berbasis

Mikrokontroler",

Palembang

http://eprints.polsri.ac.id/17

$71 /$, diakses pada tanggal

23 Agustus 2016.

Kadir, Abdul, 2013; "Panduan

Praktis

Mempelajari

Mikrokontroler dan

Pemrogramannya

Menggunakan Arduino",

Yogyakarta : Andi

Publisher.

Puspitawati,Lilis,

$$
\text { danAnggadini, } \begin{array}{r}
\text { Sri } \\
\text { Dewi, }
\end{array}
$$

2011; "Sistem Informasi

Akuntansi", Yogyakarta :

Graha IImu.

Rachmat, Antonius, C., 2010;

"Algoritma dan

Pemrograman dengan

Bahasa C", Yogyakarta :

Andi Offset.

Sugiyono,, 2010; "Metode

Penelitian Kuantitatif

Kualitatif dan $R$ \& $D$ ”,

Bandung : Alfabeta. 
Sistem Pengendalian Suhu Air Nutrisi Hidroponik Nft (Nutrient Film Tehnique) Menggunakan Sensor Suhu Dan Sms Gateway Berbasis Arduino, , Vol 12, No.1, Maret 2019.

$\begin{array}{lrr}\begin{array}{l}\text { Suryani, } \\ \text { "Hidroponik Budi }\end{array} & \text { Daya } & \text { Syahwill, Muhammad, 2013; } \\ \text { Tanaman Tanpa } & \text { Tanah } & \text { "Panduan Mudah Simulasi } \\ \begin{array}{l}\text { Mudah, Bersih, } \\ \text { Menyenangkan", }\end{array} & & \text { dan Praktek Mikrokontroler } \\ & & \text { Offset. }\end{array}$

Yogyakarta : ARCITRA. 